\title{
A NECESSIDADE DO DIÁLOGO DAS FONTES NAS RELAÇÕES DE CONSUMO SUSCETÍVEIS AO COMÉRCIO ELETRÔNICO
}

\author{
Roberto Wagner Marquesi ${ }^{1}$ \\ Isabela Cristina Sabo ${ }^{2}$ \\ Ana Paula Ruiz Silveira Lêdo ${ }^{3}$
}

\begin{abstract}
Resumo
A pesquisa abrange um estudo das legislações aplicáveis ao comércio eletrônico e a necessidade de diálogo entre elas quando da ocorrência de conflitos em relações consideradas como de consumo. Dentre os regramentos jurídicos, aborda o Marco Civil da Internet (Lei n. 12.965/2014), que impôs a aplicação de diversos princípios, garantias, direitos e deveres para o uso da internet no Brasil, inclusive aqueles relativos à proteção e defesa do consumidor (art. $2^{\circ}$, inc. $\mathrm{V}$ e art. $7^{\circ}$, inc. XIII). Também analisa, nas relações de consumo realizadas no meio virtual, a incidência do Código de Defesa do Consumidor, bem como normas do Decreto n. 7.692/2013, que regulamenta essa legislação quanto ao comércio eletrônico. Expõe, como problemática, o conflito aparente de normas em determinados casos, como a divergência dos prazos de guarda de registros previstos no $\mathrm{MCI}$ e o prazo prescricional do CDC, e a divergência das modalidades de responsabilidade civil previstas no MCI, CDC e CC, como em situações envolvendo provedores em uma relação direta de consumo e danos causados por atos de terceiros. Ao final, o trabalho demonstra que os critérios clássicos para a solução desses conflitos são insuficientes, ao passo que a resposta adequada se obtém com a aplicação da Teoria do Diálogo das Fontes, imprescindível para que haja a efetiva e correta tutela nos casos em concreto.
\end{abstract}

Palavras-chave: Comércio eletrônico; Marco Civil da Internet; Código de Defesa do Consumidor; Decreto n. 7.692/2013; Diálogo das Fontes.

\section{CONSIDERAÇÕES INICIAIS}

O consumo moderno traduz uma nova realidade social, sendo cada vez mais presente no cotidiano do homem médio por meio do comércio eletrônico ${ }^{4}$. Para tanto, algumas legislações recentes disciplinam aspectos sobre a matéria, como é o caso do Decreto n. 7.962/2013, que dispõe sobre a contratação no comércio eletrônico, e da Lei n. 12.965/2014 (Marco Civil da Internet), que estabelece princípios, garantias, direitos e deveres para o

\footnotetext{
${ }^{1}$ Doutor e Mestre em Direito Civil pela Universidade do Largo de São Francisco. E-mail: wagnermarquesi@uol.com.br

${ }^{2}$ Doutoranda pela Universidade Federal de Santa Catarina. E-mail: isabelasabo@gmail.com

${ }^{3}$ Mestra em Direito Negocial pela Universidade Estadual de Londrina. E-mail: anapaula.ruiz@hotmail.com

${ }^{4}$ A propósito, Zygmunt Bauman (2011, p. 65) alerta que o jeito de consumir das sociedades modernas do Ocidente é também o seu jeito de viver, na medida em que o comportamento social, em variados campos da vida cotidiana, foi transmutado em comportamento do consumidor, afirmando que nesse contexto, atividades sociais mais basilares, tais como a empatia e as relações mais aprofundadas, perdem espaço para busca incessante por mais dinheiro, que possibilita acesso a mais bens, os quais, segundo se acredita, traduzem-se em felicidade e realização pessoal.
} 
uso da Internet no Brasil, além das disposições presentes no Código de Defesa do Consumidor (Lei n. 8.078/1990).

Embora existam regulamentações significativas envolvendo o assunto, alguns conflitos ainda persistem, inclusive normativos, diante dos mais variados detalhes do meio virtual no momento da contratação e da própria velocidade com que as relações sociais se modificam a par do desenvolvimento tecnológico.

A exemplo, mencionar-se-á a dúvida no momento de aplicação das legislações apontadas tendo em conta o prazo dos provedores para a guarda de registros de conexão - 1 (um) ano - e registros de acesso a aplicações de internet - 6 (seis) meses -, o prazo prescricional para litígios envolvendo relações de consumo - 5 (cinco) anos - e a possibilidade de inversão do ônus da prova a favor do consumidor, prevista no art. $6^{\circ}$, inc. VIII, da lei consumerista.

Refletir-se-á, ainda, a respeito da responsabilidade civil dos agentes que operam na internet, considerando que o Marco Civil da Internet (Lei n. 12.965/2014) e o Código Civil (Lei n. 10.406/2002) disciplinam a responsabilidade dos provedores com base na culpa (subjetiva), ao passo que o Código de Defesa do Consumidor (Lei n. 8.078/1990) traz a responsabilidade dos fornecedores pelo vício e fato do produto e do serviço (objetiva), prescindindo-se a comprovação da culpa. Um exemplo é a relação envolvendo a prestação de serviços de determinado provedor de aplicações diretamente ao consumidor, o qual, eventualmente, é acometido pela atuação ilícita de terceiros, como a atuação de hackers e crackers.

Assim, será proposto nesta pesquisa, por meio do método hipotético-dedutivo, uma compreensão do que vem a ser a Teoria do Diálogo das Fontes nas relações de consumo suscetíveis ao comércio eletrônico, como meio de interpretação das atuais normas existentes a respeito do tema e de possível solução dos conflitos normativos elencados, com vistas à aplicação da lei mais adequada conforme o caso.

\section{LEGISLAÇÃO APLICÁVEL ȦS RELAÇÕES DE CONSUMO REALIZADAS NO MEIO ELETRÔNICO}

Os hábitos de consumo têm sido modificados pelo comércio eletrônico, principalmente em razão dos seus mecanismos de buscas e propagandas de produtos e serviços, bem como em razão de sua dinamização, comodidade, facilidade de acesso e pagamento, agilidade, variedade e tantas outras vantagens que o meio virtual oferece. O Brasil é um dos países que vem crescendo neste contexto e dispõe algumas normas recentes sobre o tema em seu plano interno, como é o caso do Decreto n. 7.962/2013 (que regulamenta o e-commerce) e a Lei n. 12.965/2014 (Marco Civil da Internet), além das disposições do Código de Defesa do Consumidor.

O Marco Civil da Internet (MCI) - Lei n. 12.965/2014 - "estabelece princípios, garantias, direitos e deveres para o uso da Internet no Brasil", sendo, portanto, uma lei principiológica, determinando "as diretrizes para 
atuação da União, dos Estados, do Distrito Federal e dos Municípios em relação à matéria” (art. $1^{\circ}$ ).

Ao analisar a lei, poderia se imaginar que a referida norma não trata claramente sobre comércio eletrônico em sentido estrito (quanto à compra e venda de produtos e prestação de serviços), mas apenas acerca de outras operações realizadas no comércio eletrônico em sentido amplo (como questões envolvendo a proteção à privacidade e a vedação da captação indevida de dados e da sua comercialização). Além disso, o Marco Civil da Internet, em seu art. 7º inc. XIII, reafirma a aplicação das normas de defesa do consumidor nas relações firmadas pela internet, desde que configurada uma relação de consumo (TEIXEIRA, 2015, p. 91).

Patrícia Peck Pinheiro (2013, p. 89), inclusive, pondera que o Marco Civil dá o caráter de garantia e proteção à privacidade dos usuários, pois suas informações são usadas como mercadorias no ambiente virtual, até mesmo naqueles serviços que se dizem gratuitos. Não só a privacidade é protegida, mas a segurança, a transparência nas informações, bem como todos os princípios e garantias disposta na legislação específica que regula a internet no Brasil.

A respeito do comércio eletrônico, destaca-se na legislação brasileira o Decreto n. 7.962, de 15 de março de 2013, que regulamenta o Código de Defesa do Consumidor para dispor sobre a contratação eletrônica. Ele positiva a necessidade de constar, nos sítios eletrônicos, informações claras sobre o produto, o serviço, o fornecedor, além de reiterar o atendimento facilitado ao consumidor e o respeito ao exercício do seu direito de arrependimento (art. 10).

Analisando o comércio eletrônico, Fábio Ulhoa Coelho (2012, p. 39-40) o conceitua como a venda de produtos ou a prestação de serviços realizadas por meio de transmissão eletrônica de informações. Como exemplo, pode-se mencionar a aplicação financeira feita no home banking, a compra do supermercado realizada pela internet, de flores no website da floricultura, entre outros. A natureza do bem ou serviço negociado não é relevante na definição do comércio eletrônico. Se o negócio é realizado por meio de declarações de vontade transmitidas eletronicamente, o comércio é eletrônico, porque a oferta e a aceitação ocorrem por meio da transmissão eletrônica de dados.

Ao abordar sobre a proteção do consumidor no ambiente virtual e partindo-se de definições alemãs de comércio eletrônico - "colocação eletrônica à distância" de produtos e serviços (elektronisher Fernabsatz), "tráfico negocial eletrônico" (elektronisher Geschaeftsverkehr), ou negócios através da internet (Geschaeftsverkehr über das Internet) - Cláudia Lima Marques (2004, p. 36-37) opta por utilizar a expressão "contratos do comércio eletrônico", ou ainda, "negócios jurídicos do comércio eletrônico", visto que este comércio despersonalizado, atemporal, desmaterializado e desterritorializado seria apenas um "confirmar" de negócios jurídicos unilaterais (como ofertas, publicidades direcionadas, etc.).

Ricardo Luís Lorenzetti (2004, p. 289-290) elenca as seguintes hipóteses contratuais no comércio 
eletrônico: a) entre setor público e privado (G2B - government to business): o meio eletrônico é utilizado tanto nos contratos com o Estado como entre particulares; b) entre empresas e consumidores (B2C - business to consumer): o meio eletrônico não dispensa essa distinção, sobretudo quando se fala em proteção do consumidor; c) o modo de celebração consensual (B2B - business to business ou C2C - consumer to consumer): o contrato celebrado pelo consenso das partes persiste no meio eletrônico, seja entre empresas, ou entre consumidores, visto que dois contratantes podem vincular-se mediante um computador, bem como dialogar, trocar propostas e celebrar um contrato.

De acordo com o art. 2 do Decreto n. 7.962/2013, os sites ou outros meios eletrônicos devem manter em destaque e facilmente visualizável: o seu nome empresarial e o número do CNPJ; o seu endereço físico e eletrônico, bem como outros dados para sua localização e contato; as descrições essenciais do bem, incluindo os riscos à saúde e à segurança; a especificação no preço de quaisquer adicionais, como despesas com frete ou seguro; as condições integrais da oferta, albergando a disponibilidade, formas de pagamento, maneiras e prazo de entrega ou disponibilização do produto ou de execução do serviço; as informações claras e evidentes sobre restrições ao aproveitamento da oferta.

Para garantir atendimento facilitado ao consumidor no comércio eletrônico, os arts. $4^{\circ}$ e $6^{\circ}$ do Decreto $n$. 7.962/2013 preveem que o fornecedor deverá: confirmar imediatamente o recebimento da aceitação da oferta; manter serviço eficaz de atendimento em meio eletrônico a fim de possibilitar que o consumidor obtenha informações, esclareça dúvidas, apresente reclamação, suspensão ou cancelamento do negócio (devendo a resposta ser fornecida em até cinco dias); confirmar instantaneamente o recebimento da solicitação do consumidor pelo mesmo meio utilizado por ele; disponibilizar ferramentas eficazes ao consumidor para identificação e correção instantânea de erros ocorridos nas fases anteriores à conclusão do contrato; utilizar mecanismos de segurança eficazes para pagamento e tratamento de dados do consumidor; apresentar antes da contratação um resumo do teor do contrato, com informações imprescindiveis para a escolha do consumidor, destacando as cláusulas limitativas de direitos; fornecer o contrato ao consumidor de forma que possa ser conservado e reproduzido imediatamente após a contratação; as contratações deverão observar o cumprimento dos termos da oferta, sendo que a entrega dos produtos e a prestação dos serviços respeitarão prazos, qualidade, quantidade e adequação inerente.

Em que pese as inúmeras vantagens e possibilidades do comércio eletrônico (por exemplo, escolher produtos e serviços em categorias cada vez mais amplas, obter tipos de bens personalizados, diminuição do tempo de escolha e redução dos custos de transação em benefício do consumidor), há o lado obscuro do mundo virtual caracterizado por situações em que produtos jamais chegam aos seus destinatários, clientes em uma espera infinita da devolução do dinheiro, entre outros obstáculos a prejudicar a confiança no comércio eletrônico, inclusive em 
escala global (LORENZETTI, 2004, p. 359-360). Até mesmo porque, diante das possibilidades ofertadas pelo comércio eletrônico, a distância física entre o fornecedor e o consumidor é enorme fator de enfraquecimento das informações prestadas, pois as únicas informações disponíveis ao usuário são aquelas escolhidas pelo fornecedor.

O artigo $5^{\circ}$ do Decreto n. 7.962/2013 cuida do direito de arrependimento do consumidor ao dispor que o fornecedor deve informar, de maneira ostensiva e clara, os meios pelos quais este direito pode ser exercido. $\mathrm{O}$ direito de arrependimento implica na resilição contratual sem qualquer ônus para o consumidor, podendo ser exercido pela mesma ferramenta utilizada para a contratação, sem prejuízo de outras disponibilizadas pelo fornecedor. Caberá ao fornecedor enviar ao consumidor confirmação imediata do recebimento da declaração de arrependimento. Além disso, o fornecedor deverá comunicar imediatamente a instituição financeira ou a administradora de cartão de crédito ou similar para que a operação não seja lançada na fatura do consumidor; ou, caso o lançamento já tenha sido feito, o respectivo estorno (TEIXEIRA, 2015, p. 82).

Cláudia Lima Marques (2004, p. 145-146) defende que o direito de arrependimento pode ser exercido por qualquer forma (no ambiente eletrônico, por e-mail ou um click indicando o erro). Seria um contrassenso fazer todo um esforço para reconstruir a validade e o valor probante dos meios eletrônicos para facilitar a atuação negocial dos fornecedores no mercado de consumo e exigir alguma forma especial do consumidor para exercitar seu direito. $\mathrm{O}$ fornecedor que se utiliza de meios eletrônicos à distância deve estar preparado para o erro ou a desistência do consumidor, gravando sua manifestação de vontade para seu próprio uso e limite de custos. ${ }^{5}$

Tarcisio Teixeira (2015, p. 83) observa que embora seja admitido pela doutrina e jurisprudência brasileiras o exercício do direito de arrependimento para as compras na internet, acabam aplicando-o sem distinguir os contratos cujos bens são recebidos via download dos que são remetidos ao destinatário fisicamente por transportadora ou Correios. Segundo o autor, seria muito relevante se o Decreto n. 7.962/2013 tivesse estabelecido critérios distintivos quanto às aquisições cujos bens são entregues via download ou fisicamente. Isso pois há a possibilidade de má-fé de certas pessoas que se aproveitam do recebimento virtual do bem para arrepender-se após usufruir do produto ou do serviço; ou mesmo continuar usando-o após o exercício do direito de arrependimento.

Neste contexto, verifica-se que o Decreto tem por objeto dar mais segurança aos internautas que compram pela internet, bem como estabelecer um comportamento mais adequado de vendedores, prestadores de serviço e intermediários, deixando assim as relações jurídicas mais seguras e transparentes e facilitando o acesso às informações sobre fornecedores, produtos e serviços. Sendo certo, no entanto, que sua aplicação não se dará de maneira isolada, incidindo sobre as relações consumeristas entabuladas no meio eletrônico também o Marco

\footnotetext{
${ }^{5} \mathrm{O}$ art. 49 do Código de Defesa do Consumidor prevê que o exercício do direito de arrependimento deve ser feito no prazo de 7 (sete) dias, quando a contratação ocorrer "fora" do estabelecimento comercial, especialmente por telefone ou em domicílio.
} 
Civil da Internet e o Código de Defesa do Consumidor.

\section{CONSIDERAÇÕES SOBRE A GUARDA DE REGISTROS E A RESPONSABILIDADE CIVIL DOS PROVEDORES POR ATO ILÍCITO PRATICADO POR TERCEIROS}

Após a análise das legislações brasileiras aplicáveis às relações de consumo suscetíveis ao comércio eletrônico, algumas considerações sobre pontos controvertidos na aplicação destas legislações são necessárias, como em casos envolvendo a necessidade de guarda de registro e sobre a responsabilidade civil dos provedores por danos decorrentes de conteúdo gerado por terceiros.

Há no meio virtual extrema complexidade quanto aos vários participantes envolvidos na cadeia de fornecimento, notadamente em matéria de contratação eletrônica com consumidores. Cláudia Lima Marques (2005, p. 742) ilustra como hipóteses o co-contratante, o organizador da cadeia, o representante, o provedor de acesso, o fornecedor direito do serviço ou produto, o provedor de conexão, etc.

Ou seja, a responsabilidade por danos ocasionados na internet abrange os fornecedores diretos, sejam na qualidade de empresas ou de pessoas físicas, nos termos dos arts. 12 a 20 do Código de Defesa do Consumidor. Pode atingir, ainda, na qualidade de intermediários, os provedores, os certificadores, e quaisquer agentes que, mesmo indiretamente, percebam vantagem econômica com o manuseio dos dispositivos eletrônicos pelos consumidores (como por exemplo, sites que intermediam compra e venda - MercadoLivre, Amazon.com, eBay, etc.).

Marcel Leonardi (2005, p. 79-80), ao analisar a responsabilidade civil dos provedores ${ }^{6}$, conclui que a responsabilidade por seus próprios atos deve ser interpretada através do sistema de responsabilidade previsto no Código de Defesa do Consumidor ou no Código Civil, conforme afetem diretamente os consumidores que os utilizam, ou terceiros. Já a responsabilidade civil por atos de usuários e terceiros, deve ser interpretada a par de um sistema que atribua responsabilidade solidária aos provedores em caso de dolo ou negligência, quando deixam de cumprir seus deveres (e tornam assim impossível a identificação do efetivo responsável pelo ato ilícito), quando colaboram para sua prática, ou quando deixam de bloquear o acesso à informação ilegal, após terem sido cientificados de sua existência.

Demócrito Ramos Reinaldo Filho (2005, p. 215) observa que para não ser responsabilizado solidariamente ou como coautor pela circulação desses conteúdos ilícitos, o operador do sistema deve tomar alguma iniciativa que exclua sua responsabilidade e que demonstre efetivamente que não agiu com negligência, assumindo ou endossando passivamente o conteúdo das publicações realizadas pelo usuário nos "espaços

\footnotetext{
${ }^{6}$ Segundo o autor, "[...] provedor de serviços de Internet é a pessoa natural ou jurídica que fornece serviços relacionados ao funcionamento da Internet, ou por meio dela” (LEONARDI, 2005, p. 19).
} 
privados". A comum atividade intermediária dos controladores de sistema, embora nem sempre exerça um controle real sobre o conjunto de informações que neles circulam, pode ser interpretada como implicando um conhecimento presumidor do caráter ilícito da informação que se encontra em seu sistema.

Tratam-se de posições semelhantes à adotada pela Lei n. 12.965/2014 (Marco Civil da Internet) nos arts. 19 e 21, que previu a responsabilidade subsidiária do provedor de aplicações que, notificado extrajudicialmente, não tomar as providências necessárias para indisponibilização do conteúdo danoso gerado por terceiro (art. 19). Essa comprovação será analisada em ação judicial, para fins de atribuição de responsabilidade civil (inclusive com a possibilidade de antecipação parcial ou total dos efeitos da tutela), a fim de não impedir, equivocadamente, a liberdade de expressão e de promover a censura (art. 21).

Entende-se que o provedor de aplicações é um gênero que abarca o provedor de correio eletrônico, de hospedagem, de conteúdo. O provedor de correio eletrônico é aquele que fornece serviço de envio, recebimento e armazenamento de mensagens eletrônicas. Já o provedor de hospedagem é aquele que permite o armazenamento de sites, blogs, redes sociais, etc., com textos, imagens, sons e informações em geral. E o provedor de conteúdo, por sua vez, permite ao usuário adquirir diversos produtos e serviços ao conectar-se à internet. Ao provedor de conteúdo é possível a edição das informações disponibilizadas por ele ou por terceiros, o que não ocorre no provedor de hospedagem, a quem não é possível controlar informações (TEXEIRA, 2015, p. 30, 32 e 24) (LEONARDI, 2005, p. 26).

Por aplicações de internet, compreende-se ser o conjunto de funcionalidades que podem ser acessadas por meio de um terminal conectado à internet. Essas funcionalidades correspondem, por exemplo, a sites institucionais, governamentais, empresariais de e-commerce, blogs, redes sociais, etc. Vale frisar que registros de acesso a aplicações de internet tratam-se do conteúdo de informações referentes à data e hora de uso de uma determinada aplicação de internet a partir de um determinado endereço IP (TEXEIRA, 2016, p. 93).

Realizadas as diversificações dos espécimes de provedores, pontuadas algumas questões a respeito das diferenças de responsabilização, é interesse desta pesquisa apurar dois assuntos conflituosos. O primeiro diz respeito aos prazos de guarda de registro estipulados no Marco Civil da Internet em contraposição ao prazo prescricional para o ingresso de ação de responsabilização pelos danos causados em relação de consumo no ambiente eletrônico, observando-se também a inversão do ônus comprobatório, previstos no Código de Defesa do Consumidor. O segundo, ainda com relação à responsabilidade civil, aborda a modalidade de responsabilização dos provedores, especificamente em uma relação de consumo envolvendo atos de terceiros: se subjetiva ou objetiva, de acordo com o Marco Civil da Internet, com o Código Civil e com o Código de Defesa o Consumidor.

Em seu Capítulo III, dispondo sobre a provisão de conexão e de aplicações de internet, o Marco Civil da 
Internet regulamenta, na Seção II, a respeito da proteção aos registros, aos dados pessoais e às comunicações privadas, atentando para questões relativas à guarda de registros de conexão, na subseção I, e para a guarda de registros de acesso a aplicações de internet na provisão de conexão, na subseção II. Para tanto, a lei estabelece como prazo de guarda para registros de conexão o período de 1 (um) ano (art. 13), impedindo que essa responsabilidade seja transferida a terceiros (artigo 13, $\$ 1^{\circ}$ ), sendo necessária, entretanto, para a disponibilização dos registros, uma autorização judicial $\left(\operatorname{art.} 13, \mathbb{S} 5^{\circ}\right.$ ). Já em relação ao prazo de guarda de registros de acesso a aplicações de internet na provisão de aplicações, é necessária a guarda pelo período de 6 (seis) meses (art. 15), também necessitando de autorização judicial a disponibilização ao requerente dos registros solicitados.

Não se verifica problema nem contradição legislativa nos dispositivos mencionados. Aliás, acredita-se que os prazos de guarda de registros estabelecidos pelo Marco Civil da Internet sejam coerentes com as especificidades do meio eletrônico, com toda a sua dinamicidade e, principalmente, levando-se em conta o alto custo para o arquivo de incontáveis - hiperbolizando, logicamente - dados que devem ser guardados pelos provedores. A problemática surge quando houver a incidência de ação de responsabilização em razão da relação entre o consumidor e o fornecedor na internet. Isso em razão da lei consumerista determinar como prazo prescricional para o ajuizamento da ação o período de 5 (cinco) anos (art. 27), geralmente com a inversão do ônus da prova, quando verificada a vulnerabilidade do consumidor.

Não é dificil perceber a incompatibilidade do direito material, posto na lei especial sobre internet no Brasil (Marco Civil da Internet), com o prazo prescricional de 5 (cinco) anos para ingresso de ação de ressarcimento, analisado com a inversão do ônus da prova, ambos estabelecidos pela lei especial sobre relação de consumo (Código de Defesa do Consumidor): sendo obrigados a guardar registros de acesso dos consumidores sob sigilo pelos prazos de 6 (seis) meses ou 1 (um) ano, de acordo sua espécie, os provedores, após o decurso desse tempo, logicamente, tornam-se desobrigados (legalmente) a manter sob guarda tais arquivos. No entanto, caso sejam demandados judicialmente após o período estipulado pelo Marco Civil da Internet, ou seja, nos 4 (quatro) anos ou 4 (quatro) anos e meio seguintes, e seja aplicada a inversão do ônus da prova, os provedores ficarão impossibilitados de arcarem com a incumbência comprobatória, pois não mais possuirão os registros que mantinham, vez que desobrigados após o transcurso do prazo estabelecido.

Cuidado também deve ser tomado ao analisar a temática da modalidade de responsabilidade civil dos operadores de internet no Brasil, especialmente no que tange às relações de consumo. Durante muito tempo não houve a necessidade de preocupação com este tema, pois incontroversa, diante da ausência de lei especializada sobre o uso da internet no território brasileiro em sentido diverso. Na ocorrência de algum dano nas relações de consumo eletrônicas, ou seja, havendo fato (ato ilícito) que gerasse dano, observado o nexo de causalidade entre 
os dois elementos, incidiria a responsabilidade civil na modalidade objetiva, sem a aferição da culpa do ofensor ${ }^{7}$ (ROSENVALD, 2008, p. 467). Isso de acordo com a regra geral de responsabilidade civil objetiva preconizada pelo Código de Defesa do Consumidor, em seu art. 14.

No entanto, com a promulgação do Marco Civil da Internet, em 2014, surgiu a necessidade de se averiguar qual a modalidade de responsabilidade civil deveria ser aplicada aos provedores em razão da ocorrência de danos causados aos consumidores. De acordo com o art. 10, inc. VI, a referida lei dispõe a "responsabilização dos agentes de acordo com suas atividades, nos termos da lei", não revelando, expressamente, qual a modalidade de responsabilidade. Entretanto, numa análise lógica, entende-se pela responsabilidade subjetiva, pelos seguintes motivos.

A regra geral de responsabilidade civil é a subjetiva, disposta no art. 186 do Código Civil, em sua parte geral. Também, nesta mesma análise, de acordo com o parágrafo único, primeira parte, do artigo 927 do Código Civil, a responsabilidade civil objetiva é exceção que só será aplicada nos casos previstos em lei. Logo, sendo o Marco Civil da Internet lei específica, trazendo dispositivo legal exclusivo acerca da responsabilidade civil dos agentes da internet, entende-se que, diante da inexpressão da modalidade objetiva, a modalidade de responsabilidade civil almejada pelo legislador é a subjetiva ${ }^{8}$, devendo, desta forma, ser verificada a culpa destes

\footnotetext{
7 Confirmando a afirmação: REPARAÇÃO DE DANOS - RESPONSABILIDADE CIVIL - INTERNET - ORKUT APLICABILIDADE DO CDC - CRIAÇÃO DE COMUNIDADE PARA DIFAMAÇÃO - MANUTENÇÃO DA COMUNIDADE - ATO ILÍCITO - SERVIÇO FALHO - DANO MORAL - PRINCÍPIO DA RAZOABILIDADE E DA PROPORCIONALIDADE - RECURSO DESPROVIDO. A relação que se estabelece entre a empresa que fornece um site de hospedagem gratuito e o usuário que usufrui desse serviço é de consumo, sendo perfeitamente aplicável o CDC, pois, apesar de não ser remunerado, a empresa recebe pagamento de terceiros, que fazem propaganda visando o usuário, portanto, estabelecendo uma relação de consumo indireta. Sendo aplicável o CDC, a empresa responde pelos danos causados, mesmo que não aja com culpa ou dolo, conforme estabelece o art. 14 do referido código. Comprovado o nexo causal entre o dano causado e a má prestação do serviço, gera para a empresa o dever de indenizar pelo dano moral sofrido pela parte. (TJMT, Apelação Cível n. 110090/2010, Rel. Des. Carlos Alberto Alves da Rocha, 5 a Câmara Cível, Julgado em 03/08/2011, Publicado no DJE em 11/08/2011).

${ }^{\circ}$ Neste sentido: RECURSO ESPECIAL. OBRIGAÇÃO DE FAZER E REPARAÇÃO CIVIL. DANOS MORAIS E MATERIAIS. PROVEDOR DE SERVIÇOS DE INTERNET. REDE SOCIAL "ORKUT". RESPONSABILIDADE SUBJETIVA. CONTROLE EDITORIAL. INEXISTÊNCIA. APRECIAÇÃO E NOTIFICAÇÃO JUDICIAL. NECESSIDADE. ART. 19, \$ 1, DA LEI No 12.965/2014 (MARCO CIVIL DA INTERNET). INDICAÇÃO DA URL. MONITORAMENTO DA REDE. CENSURA PRÉVIA. IMPOSSIBILIDADE. RESSARCIMENTO DOS HONORÁRIOS CONTRATUAIS. NÃO CABIMENTO. 1. Cuida-se de ação de obrigação de fazer cumulada com indenização por danos morais e materiais, decorrentes de disponibilização, em rede social, de material considerado ofensivo à honra do autor. 2. A responsabilidade dos provedores de conteúdo de internet em geral depende da existência ou não do controle editorial do material disponibilizado na rede. Não havendo esse controle, a responsabilização somente é devida se, após notificação judicial para a retirada do material, mantiver-se inerte. Se houver o controle, o provedor de conteúdo torna-se responsável pelo material publicado independentemente de notificação. Precedentes do STJ. 3. Cabe ao Poder Judiciário ponderar os elementos da responsabilidade civil dos indivíduos, nos casos de manifestações de pensamento na internet, em conjunto com o princípio constitucional de liberdade de expressão (art. 220, $\$ 2^{\circ}$, da Constituição Federal). 4. A jurisprudência do STJ, em harmonia com o art. 19, $\$ 1^{\circ}$, da Lei no 12.965/2014 (Marco Civil da Internet), entende necessária a notificação judicial ao provedor de conteúdo ou de hospedagem para retirada de material apontado como infringente, com a indicação clara e específica da URL - Universal Resource Locator. 5. Não se pode impor ao provedor de internet que monitore o conteúdo produzido pelos usuários da rede, de modo a impedir, ou censurar previamente, a divulgação de futuras manifestações ofensivas contra determinado indivíduo. 6. A Segunda Seção do STJ já se pronunciou no sentido de ser incabível a condenação da parte sucumbente aos honorários contratuais despendidos pela
} 
agentes para que haja o dever de ressarcir (CAVALIERI FILHO, 2015, p. 150), ainda que a legislação não exclua a incidência das normas consumeristas ao comércio eletrônico (art. 7o , inc. XIII).

Além disso, conforme exposto, interpreta-se que o Marco Civil da Internet, em seus arts. 19 e 21, determina a responsabilização dos provedores de aplicações por danos decorrentes de conteúdo gerado por terceiros se (i) após ordem judicial específica, não tomarem as providências para, no âmbito e nos limites técnicos do seu serviço e dentro do prazo assinalado, tornarem indisponível o conteúdo apontado como infringente, ressalvadas as disposições legais em contrário (art. 19); ou se (ii) após o recebimento de notificação pelo participante ou seu representante legal, deixarem de promover, de forma diligente, no âmbito e nos limites técnicos do seu serviço, a indisponibilização desse conteúdo (art. 21), está prevendo uma conduta omissiva, de negligência ou imprudência prevista no art. 186 do Código Civil. Ou seja, está prevendo responsabilidade baseada na comprovação de culpa, porquanto subjetiva.

Todavia, há ainda certa dificuldade na definição dessa modalidade em determinados casos caracterizados como relações de consumo. Um deles é a relação direta entre consumidor e provedor de hospedagem ou de conteúdo, cuja segurança integrante do negócio é quebrada pela atuação de terceiros (hackers ou crackers $^{9}$ ) que, na vulnerabilidade do sistema, conseguem adentrá-lo e gerar conteúdo impróprio.

Percebe-se o conflito de normas a partir das seguintes considerações: o Marco Civil da Internet, conforme exposto, dispõe a responsabilidade subjetiva dos provedores por atos ilícitos praticados por terceiros em seu âmbito (arts. 19 e 21); o Código Civil, também, dispõe a responsabilidade subjetiva como regra (art. 186); o Código de Defesa do Consumidor dispõe a responsabilidade objetiva dos fornecedores por fato do produto ou do serviço (arts. 12 e 14), elencando a possibilidade de eliminação dessa responsabilidade quando por culpa

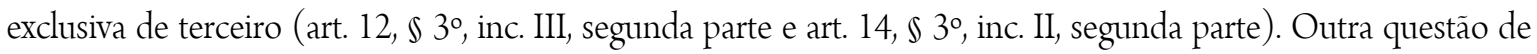
relevância neste caso é análise do risco: se ele faz parte da atividade econômica e, portanto, gerador de responsabilidade em razão da possibilidade de prevê-lo anteriormente; ou se ele faz parte do desenvolvimento veloz das tecnologias e, portanto, excludente de responsabilidade em razão da impossibilidade de prevê-lo anteriormente.

A seguir será abordado a respeito dos critérios tradicionais de solução de conflitos, bem como acerca da Teoria do Diálogo das Fontes como melhor resposta para os exemplos mencionados, visto não excluir nenhuma norma, mas sim aplica-las simultaneamente, buscando a melhor tutela para o caso concreto.

vencedora. 7. Recurso especial provido (STJ, REsp n. 1568935 RJ 2015/0101137-0, Rel. Min. Ricardo Villas Bôas Cueva, $3^{\text {a }}$ Turma, Julgado em 05/04/2016, Publicado no DJE em 13/04/2016).

${ }^{9}$ Embora ambas as figuras causem transtornos, há uma importante diferença para fins de efeitos jurídicos: os crackers atuam de forma manifestamente dolosa, objetivando prejudicar o consumidor ou tirar proveito de uma informação obtida; não se confundem com os hackers, os quais são igualmente capazes de invadir computadores alheios, como também de impedir eventuais invasões (TEIXEIRA, 2014, p. 378-379). 


\section{CONFLITO APARENTE DE NORMAS: A NECESSIDADE DO DIÁLOGO DAS FONTES}

O cenário atual é marcado por uma hipercomplexidade das relações, principalmente em razão do pluralismo trazido pela globalização e, em consequência dela (ou fator determinante para que ela se desenvolvesse), pela interação e dinamicidade ocasionada pelos adventos tecnológicos, possibilitando maior velocidade de informações e comunicação a nível mundial. A contemporaneidade traduz um período de transformações jurídicas que surgem a par das modificações pelas quais passam a sociedade, sendo que conceitos e institutos jurídicos que remetiam ao século XIX são desafiados a oferecer respostas em um mundo tecnologicamente avançado. Para dar conta deste desafio, os estudiosos das ciências jurídicas, elaboram reflexões constantemente, a fim de conceber modelos que deem conta das demandas da sociedade na era da tecnologia, e que retornem com melhor solução para os conflitos surgidos.

As diversas possibilidades de exercício da autonomia privada dos sujeitos nesse ambiente desafiam os operadores do direito a refletirem sobre qual a melhor maneira de se oferecer tutela a conflitos existentes nessa realidade. Alguns defendem a positivação de cada vez mais legislações a fim de que abarquem todas estas novas situações originadas, especialmente, em razão do advento tecnológico, para que fosse possível a realização da mera subsunção do fato à norma para resolver os possíveis conflitos. Outros entendem pela adoção de cláusulas gerais ${ }^{10}$, como se tem sido observado na Constituição Federal, no Código Civil e no Código de Defesa do Consumidor, a exemplo as cláusulas gerais da tutela da dignidade da pessoa humana, da função social e da boa-fé objetiva (MARQUES, 2005, p. 220).

Sobre a teoria da subsunção, aliás, Karl Larenz (1966, p. 154) afirma que "ninguém mais pode afirmar seriamente que a aplicação das leis nada mais envolva do que uma inclusão lógica sobre conceitos superiores abstratamente formulados", tendo em vista que nem toda decisão jurídica é uma questão de mera subsunção do caso particular a uma norma geral ${ }^{11}$. Até mesmo porque, em determinados conflitos, haverá a possibilidade da incidência de várias legislações, sendo esse um problema para esta teoria: a qual norma subsumir determinado caso em concreto, quando disciplinado por diversas normas?

\footnotetext{
${ }^{10}$ Francisco dos Santos Amaral Neto (2004, p. 17) explica que "O sistema de cláusulas gerais constitui um modelo que promove uma ruptura com o sistema que prevaleceu até meados do Século XX, em que a segurança jurídica residia na positivação do direito por meio de normas escritas que buscavam tutelar todas as relações jurídicas existentes na sociedade. [...] As cláusulas gerais são preceitos jurídicos vazios e incompletos que, graças à sua generalidade e abstração, podem abranger um vasto grupo de situações de modo lacunar e com a possibilidade de ajustamento a uma consequência jurídica.”.

${ }^{11}$ No mesmo sentido, Robert Alexy (2001, p. 17-19) menciona que "Há casos em que a decisão de um caso isolado não segue logicamente quer de afirmações empíricas tomadas junto com normas pressupostas ou proposições estritamente fundamentadas de algum sistema de raciocínio (juntamente com proposições empíricas), nem pode essa decisão ser totalmente justificada com a ajuda das regras de metodologia jurídica; nesses casos deve-se concluir que quem decide tem de ser discreto, na medida em que o
} 
Num primeiro momento, acreditou-se que os critérios de solução de conflito aparente de antinomias de normas seriam suficientes: lex posterior derogat priori, lex superior derogat inferior e lex specialis derogat generali, ou seja, o critério da cronologia, pelo qual lei posterior derroga lei anterior; o critério da hierarquia, onde lei hierarquicamente superior derroga lei inferior; e o critério da especialidade, segundo o qual lei especial derroga lei geral (BOBBIO, 1999, p. 91-114). Aplicando-se tais critérios ao conflito diante do caso em concreto, verificar-se-ia qual norma a ele deveria ser aplicada. Entretanto, não é difícil imaginar que estes critérios, diante de determinados conflitos aparentes de normas, poderiam ser insuficientes. É o que ocorre com os casos apresentados no capítulo 2 desta pesquisa, em que se verifica a possibilidade de incidência de duas normas competentes para disciplinar o assunto comércio eletrônico (Marco Civil da Internet e Código de Defesa do Consumidor). Entretanto, mesmo com a aplicação dos critérios cunhados por Norberto Bobbio, ainda há divergência jurisprudencial sobre qual norma aplicar.

Veja-se:

1. Critério da cronologia: Código de Defesa do Consumidor, Lei no 8.078 , foi promulgada em11 de setembro de 1990, já o Marco Civil da internet, Lei no 12.965, foi promulgado em 23 de abril de 2014.

2. Critério da hierarquia: Código de Defesa do Consumidor e Marco Civil da Internet: leis ordinárias, hierarquicamente iguais.

3. Critério da especialidade: Código de Defesa do Consumidor é lei geral a respeito de relações de consumo $^{12}$, enquanto o Marco Civil da Internet é lei especial sobre todas os princípios, garantias, direitos e deveres concernentes ao uso da internet no Brasil, inclusive no que tange às relações de consumo no ambiente virtual.

Diante desta análise, certo seria que se aplicasse, sem dúvidas, o Marco Civil da Internet em detrimento da aplicação normativa do Código de Defesa do Consumidor, vez que aquele é vencedor em dois dos três critérios (cronologia e especialidade) e empata com este no critério da hierarquia. No entanto, não é simples assim. Sobre o assunto, Cláudia Lima Marques (2005, p. 632) ensina que se deve ter cautela ao realizar a análise do conflito aparente de normas e a aplicação dos critérios para sua solução, quando envolvidas leis especiais novas em relação ao Código de Defesa do Consumidor. Para a autora, não há revogação tácita da lei geral anterior (CDC) com a vigência da lei nova (importante para esta pesquisa, o MCI), pois:

Revogá-la significaria inaplicar a lei geral a outras matérias importantes. A lei especial nova, porém, pode afastar, em caso de antinomia verdadeira, a aplicação da lei geral anterior. Notese que a antinomia é um conflito limitado e típico e que ambas as leis aplicam-se ao caso concreto, prevalecendo a especial posterior no que regula e o regime geral (não

caso não seja completamente regido por normas jurídicas, regras do método jurídico e doutrinas de dogmática jurídica. Então ele pode escolher entre várias soluções.".

${ }_{12}$ Claudia Lima Marques (2006, p. 631) defende que o Código de Defesa do Consumidor é visualizado como "[...] lei 'geral' de tutela dos consumidores em todos os contratos e relações de consumo”. 
incompatível) da lei geral ou especial anterior, se hierarquicamente iguais (MARQUES, 2005, p. 632).

Ou seja, a aplicação dos critérios apresentados, apenas, é insuficiente. A questão permanece sem resposta: a qual norma subsumir determinado caso em concreto, quando disciplinado por diversas normas? Segundo Cláudia Lima Marques (2005, p. 585), foi com este questionamento que Erick Jayme, na Alemanha, elaborou a Teoria do Diálogo das Fontes, para que se possibilitasse uma interação entre as Diretivas da União Europeia e as leis internas. No Brasil, a autora foi precursora da teoria, afirmando que as leis não se excluem, mas se comunicam. Trazendo aqui um conceito mais abrangente impresso pela autora, que define o diálogo das fontes como:

'Diálogo' porque há influências recíprocas, 'diálogo' porque há aplicação conjunta das duas normas ao mesmo tempo e ao mesmo caso, seja complementarmente, seja subsidiariamente, seja permitindo a opção pela fonte prevalente ou mesmo permitindo uma opção por uma das leis em conflito abstrato - solução flexível e aberta, de interpenetração, ou mesmo a solução mais favorável ao mais fraco da relação (tratamento diferente dos diferentes) (MARQUES, 2012, p. 118).

Existem três possibilidades de diálogos entre fontes: a primeira hipótese é chamada de diálogo sistemático de coerência, ocorrendo quando houver aplicação simultânea de duas leis, na qual uma serve de base de conceitos para a outra. A segunda é o diálogo de complementariedade, quando for realizado de maneira direta, ou de diálogo de subsidiariedade, quando de maneira indireta, quando uma norma complementa a outra. Por fim, a última hipótese de diálogo cunhada pela autora é chamada de o diálogo de influências recíprocas sistemáticas, que ocorrerá quando conceitos estruturais de uma lei são influenciados por outras leis (MARQUES, 2005, p. 693694).

Ao analisar a teoria, Flávio Tartuce (2012, p. 66), menciona que ela “[...] surge para substituir e superar os critérios clássicos de solução de antinomias jurídicas (hierárquico, especialidade e cronológico)", sendo esse "seu papel para o futuro". Em razão da pluralidade de leis contemporâneas que atuam de maneira convergente e flexível, abarcando uma mesma relação jurídica, não há como se satisfazer com a escolha de apenas uma delas, devendo aplicá-las conjuntamente, naquilo que thes couber (MARQUES, 2005, p. 588).

Volta-se a atenção aos casos apresentados no capítulo 2, nos quais há conflito aparente entre a aplicação do Marco Civil da Internet e/ou do Código de Defesa do Consumidor. Passa-se a aplicar a Teoria do Diálogo das Fontes.

Em relação à questão do prazo de guarda de registro (seis meses ou um ano) definidos no Marco Civil da Internet e o prazo prescricional (cinco anos) e inversão do ônus da prova previstos no Código de Defesa do Consumidor, como ficaria o provedor nos casos em que o consumidor promovesse a demanda judicial após o decurso do prazo de guarda dos registros, mas dentro do prazo prescricional previsto na lei consumerista? E ainda, como seria esse provedor capaz de ser incumbido do ônus comprobatório? Entende-se como solução mais 
adequada, utilizando-se do diálogo das fontes, mas não apenas com o seu caráter instituído por Cláudia Lima Marques, já mencionado, de proteção última à parte vulnerável, mas sim como solução adequada aos casos concretos. No caso, a aplicação das duas legislações em conjunto realizada da seguinte forma, observadas duas situações: 1) Consumidor promove a demanda judicial contra o provedor dentro do prazo de guarda de registros estabelecido pelo Marco Civil da Internet: aplica-se o MCI juntamente com o CDC, devendo-se, neste caso, observados os requisitos legais, haver a inversão do ônus da prova. 2) Consumidor promove a demanda judicial contra o provedor após o prazo de guarda de registro estabelecido pelo Marco Civil da Internet: aplica-se o MCI juntamente com o CDC, porém, neste caso, desincumbido do arquivo dos registros, impossível seria a aplicação da inversão do ônus comprobatório, devendo este ônus recair sobre o consumidor.

Quanto à responsabilidade civil dos provedores de hospedagem e conteúdo em relação envolvendo o consumidor diretamente, o qual tem a segurança fornecida afetada pela atuação ilícita de terceiros (hackers e crackers), antes de aplicar o diálogo das fontes, são necessárias as seguintes considerações.

Conforme salientado, a responsabilidade objetiva, fundamentada na teoria do risco criado, foi concebida como exceção, e não como regra. Marcel Leonardi (2005, p. 44) afirma que ampliar demasiadamente seu campo de aplicação criará enorme insegurança jurídica. Se qualquer atividade humana for considerada como passível de criar risco para os direitos de outrem, restará esvaziado o sistema de responsabilidade subjetiva. Consequentemente, haverá motivo para a adoção de cautelas objetivando a prevenção de danos, já que o dever de indenizar existirá independentemente das medidas de segurança tomadas pelo agente.

Essa é a ideia adotada pelo Marco Civil da Internet quanto ao provedor de aplicações, gênero de provedor de hospedagem e conteúdo. Para o referido autor, a responsabilidade civil em ambos os provedores por atos ilícitos praticados por seus usuários ou terceiros é subjetiva, advindo apenas de eventual conduta omissiva, de negligência ou imprudência, tendo aplicação o art. 186 do Código Civil. Isto ocorrerá quando o provedor de hospedagem ou de conteúdo deixar de bloquear o acesso à informação ilegal disponibilizada por um usuário, ou quando não o fizer em tempo hábil, desde que tenha sido previamente informado a esse respeito e desde que não haja dúvidas sobre a ilicitude da conduta perpetrada pelo usuário (LEONARDI, 2005, p. 105 e 110).

A situação será diferente quanto ao provedor de conteúdo (em razão de sua capacidade de modificação das informações), se ele auferir alguma vantagem ou lucro em razão de funcionar como intermediário de uma transação comercial ou, ainda, em razão de prática criminosa diretamente relacionada com a conduta de seus usuários. No primeiro caso ele responderá sob o regime consumerista, por fazer parte da cadeia de fornecedores, como é o caso de empresas que abrem espaço para terceiros anunciarem seus produtos e serviços, recebendo parte do lucro obtido na venda; no segundo, ele responderá de acordo com o art. 932, inc. V e art. 933 do Código Civil, ou seja, ainda que não haja culpa de sua parte, aplicando-se a responsabilidade objetiva (LEONARDI, 2005, 
p. 110).

Por outro lado, o Código de Defesa do Consumidor traz a possibilidade de exclusão da responsabilidade civil por fato de terceiro ( $\operatorname{art} .12, \$ 3^{\circ}$, inc. III, segunda parte e art. $14, \$ 3^{\circ}$, inc. II, segunda parte). Terceiro, em uma relação de consumo virtual, é alguém sem qualquer vínculo com o fornecedor, sendo completamente estranho à cadeia de consumo. Cabe observar que em uma página contendo a oferta pública de produtos e serviços online ou a proposta via e-mail, não são terceiros os chamados intermediários da contratação eletrônica, em especial o provedor e o certificador, principalmente naquilo que diga respeito ao serviço por estes prestado. Fatos como a contaminação por vírus ou a propagação de spam podem consubstanciar a participação total ou parcial do terceiro no dano; apenas no primeiro caso, uma vez ocorrendo a eliminação do nexo causal, é que fica excluída a responsabilidade do fornecedor (MARTINS, 2008, p. 147-148).

José de Aguiar Dias (1979, p. 85-86), a respeito da culpa exclusiva de terceiro, afirma que "[...] desfaz em relação ao indigitado responsável a causalidade e, sem causalidade, seja objetivo, seja subjetivo o critério a adotar, não se pode reconhecer a obrigação de indenizar". Assim, depreende-se que a atuação de hackers e crackers, seja na responsabilidade subjetiva, ou na responsabilidade objetiva, elimina o nexo causal e portanto, elimina qualquer dever de reparar o dano por parte dos provedores. A previsão também está, indiretamente, no Marco Civil da Internet, pois enquanto o provedor de aplicações não tiver sido notificado extrajudicialmente, ou, na ausência desta, citado/intimado judicialmente, não será responsabilizado.

Entretanto, há outra discussão incidente no caso, sobre a qual a doutrina ainda não se posicionou definitivamente: o risco do desenvolvimento. Nas palavras de Guilherme Magalhães Martins:

Consiste o risco do desenvolvimento na possibilidade de um produto ser introduzido no mercado sem possuir defeito cognoscível (ainda que exaustivamente testado, ante o grau de conhecimento disponível à época de sua introdução), sendo detectado defeito, depois de determinado período do início de sua circulação no mercado de consumo, somente identificável ante a evolução dos meios técnicos e científicos, capaz de causar danos aos consumidores. A relevância de tal excludente, para os fins deste trabalho, refere-se sobretudo ao fornecimento de produtos e serviços ligados à segurança das relações contratuais celebradas por meio eletrônico na Internet, tais quais as firewalls, programas antivírus ou filtros anti-spam - no tocante aos dois últimos, especialmente se houver específica obrigação contratual assumida pelo provedor no sentido da sua prestação [...]" (MARTINS, 2008, p. 164).

No caso da atuação de hackers e crackers em sistemas informáticos, há opiniões das mais diversas. Alguns defendem que as empresas que fornecem produtos e serviços relacionados à tecnologia da informação têm condições de prever esse risco e adotar medidas de segurança atualizadas para que a invasão não ocorra. No entanto, há que se observar, também, que os sistemas informáticos se tornam vulneráveis a cada dia e que novas descobertas no campo da tecnologia ocorrem a todo instante. Logo, deve-se ponderar a possibilidade da empresa, mesmo dispondo mecanismos de proteção dos mais altos níveis até então, ser surpreendida com o ataque de invasores a parir de uma falha não identificada anteriormente. 
O risco de desenvolvimento, segundo Guilherme Magalhães Martins, deve ser considerado excludente de responsabilidade, mesmo na ausência de dispositivo legal expresso. $\mathrm{O}$ autor remete à Gustavo Tepedino, ao afirmar que, do contrário, seria uma hipótese extrema cuja assunção será insuportável para o setor produtivo da sociedade, desencorajando a comercialização de certos produtos. Nas palavras do autor citado, releva-se o interesse da sociedade no sentido de um crescente e constante aprimoramento da ciência, devendo os riscos advindos das novas tecnologias ser absorvidos por todo o corpo social. Logo, seria lícito ao fornecedor inserir no mercado de consumo produtos que não saiba, e nem deveria saber, resultarem perigosos, diante do grau de desenvolvimento científico à época de sua introdução no mercado, standard esse que serve, ao mesmo tempo, como limite para a expectativa de segurança do consumidor (MARTINS, 2008, p. 168-169).

Por essa razão, em relações de consumo virtuais, a rápida mutação e evolução das tecnologias é um fato decisivo para a exclusão da responsabilidade do fornecedor, desde que sua periculosidade se revele de verificação objetivamente impossível. Tendo em vista esse fator, torna-se praticamente impossível a determinação da capacidade de desenvolvimento das técnicas e, para cada avanço em matéria de tecnologias de segurança, outro surge de modo a quebra-lo. De qualquer forma, é imprescindível a verificação do estado da técnica no momento da ocorrência do evento danoso em contraposição à época em que o produto foi colocado em circulação, com o intuito de aferir a periculosidade (MARTINS, 2008, p. 169).

Feitas essas considerações a respeito da responsabilidade subjetiva interpretada do Marco Civil da Internet, da responsabilidade objetiva prevista no Código de Defesa do Consumidor, da possibilidade de exclusão por fato de terceiro e por risco do desenvolvimento, a partir da Teoria do Diálogo das Fontes, soluciona-se o conflito da seguinte maneira:

1) Tratando-se de atuação de hackers ou crackers que ocasionem danos ao consumidor, o provedor de hospedagem e o provedor de conteúdo que dentre os serviços contratados por ele está a prestação de segurança de suas informações, serão responsabilizados somente caso não retirem o conteúdo danoso após notificado extrajudicialmente ou, na ausência desta, após ordem judicial (responsabilidade subjetiva), de acordo com o MCI. 2) Se o conteúdo for produto de crime, o provedor de conteúdo, apenas, responderá independentemente de notificação ou ordem judicial prévia (responsabilidade objetiva), de acordo com o CC. 3) Se houver lucro ou vantagem econômica obtida diretamente do consumidor, o provedor de conteúdo, apenas, responderá independentemente de notificação ou ordem judicial prévia (responsabilidade objetiva), de acordo com o CDC. E, finalmente, 4) na impossibilidade de indisponibilização/retirada do conteúdo danoso, ou na impossibilidade de retorno da vítima ao estado anterior ao ato ilícito, o provedor de hospedagem e o provedor de conteúdo serão responsabilizados se comprovado que haviam, no momento do dano, meios de segurança eficazes e disponíveis para evita-lo. 
Portanto, é certo que a aplicação da Teoria do Diálogo das Fontes é um avanço para que se consiga tutelar de maneira eficiente as relações de consumo entabuladas no mundo pós-moderno. Diferente não seria em relação ao comércio eletrônico, aplicando-se, conjuntamente, o Marco Civil da Internet, o Código de Defesa do Consumidor e o Código Civil.

\section{CONSIDERAÇÕES FINAIS}

A dinamicidade das relações de consumo realizadas no ambiente virtual acarreta a necessidade de interpretação de algumas normas, principalmente levando-se em conta a hipercomplexidade do cenário contemporâneo no qual elas se realizam. Isto porque esse cenário é marcado pela velocidade de informações e comunicação, decorrentes do mundo globalizado, o que interfere diretamente nas transformações jurídicas, trazendo um maior número de legislações a fim de tentar regular novas relações jurídicas que se manifestam.

É nesse contexto que se apresentou nesta pesquisa três legislações incidentes ao comércio eletrônico: o Marco Civil da Internet, o Código de Defesa do Consumidor e Decreto 7.962/2013, que regulamenta o CDC quanto àquela matéria, sendo fato incontroverso a aplicação das legislações mencionadas. No entanto, verificou-se que em algumas questões suscetíveis às relações de consumo realizadas via internet pode-se observar a existência de um conflito aparente de normas, como acontece com os prazos de guarda de registros do MCI e o prazo prescricional do CDC, bem como sobre a espécie de responsabilidade civil a ser aplicada aos provedores nos casos de ato ilícito praticado por terceiros, momento em que verificou-se a incidência do MCI, do CDC e do CC.

Foi constatado que tais conflitos não se resolvem com a aplicação dos critérios clássicos para solução de antinomia aparente de normas cunhados por Norberto Bobbio (cronologia, hierarquia e especialidade), restando, ainda, a dúvida ao operador do direito sobre em qual legislação subsumirá o caso em concreto. Diante disso, o trabalho revelou que solução adequada se encontra na Teoria do Diálogo das Fontes, de Erick Jayme, trazida para o Brasil por Cláudia Lima Marques, pela qual se aplicam as normas de maneira conjunta, dialogante.

Ao realizar o mencionado diálogo nas questões levantadas, entendeu-se, quanto aos prazos de guarda de registros do Marco Civil da Internet, e o prazo prescricional e inversão do ônus da prova, dispostos no Código de Defesa do Consumidor, haveria de ser realizado tal diálogo observadas as hipóteses que consideram o momento do ingresso da ação do consumidor contra o provedor. Estando dentro do prazo de guarda previsto, o diálogo seria realizado de maneira completa, invertendo-se, inclusive, o ônus da prova; ultrapassado o prazo de guarda de registro, entretanto, concluiu-se pela impossibilidade de que fosse invertido o ônus comprobatório, recaindo este sobre o consumidor, ainda que parte vulnerável da relação.

Quanto à responsabilidade civil dos provedores de aplicações, enquanto gênero do provedor de hospedagem e de conteúdo, em relações de consumo envolvendo a prestação de segurança das informações, e 
eventual atuação ilícita de terceiros, entendeu-se que a responsabilidade será subjetiva, e somente será aplicada em caso de recusa do provedor em tornar indisponível o conteúdo ilícito gerado. Todavia, em casos em que houver vantagem econômica direta do consumidor ou quando o conteúdo ilícito for produto de crime, a responsabilidade será objetiva, e somente será aplicada ao provedor de conteúdo. Por fim, na impossibilidade de retirada do conteúdo ilícito ou retorno da vítima ao estado anterior à prática ato, somente haverá responsabilidade quando comprovado que o provedor de hospedagem e o provedor de conteúdo possuíam meios disponíveis e eficazes, dentro de suas condições técnicas, de evitarem o dano.

\title{
THE NEED FOR DIALOGUE OF SOURCES IN CONSUMER RELATIONS SUSCEPTIBLE TO ELECTRONIC COMMERCE
}

\begin{abstract}
The research encompasses a study of the laws applicable to electronic commerce and the need for dialogue between them when conflicts occur in relations considered as consumption. Among the legal regulations, it addresses the Civil Internet Framework (Law No. 12.965 / 2014), which imposed the application of various principles, guarantees, rights and duties for the use of the Internet in Brazil, including those related to consumer protection and protection (article 2, paragraph $\mathrm{V}$ and article 7, item XIII). It also analyzes, in consumer relations carried out in the virtual environment, the incidence of the Consumer Defense Code, as well as the norms of Decree no. 7.692 / 2013, which regulates this legislation in electronic commerce. It exposes, as problematic, the apparent conflict of norms in certain cases, such as the divergence of the record keeping periods foreseen in the ICM and the CDC prescriptive period, and the divergence of the types of civil liability foreseen in ICM, CDC and $\mathrm{CC}$, as in situations involving providers in a direct relationship of consumption and damages caused by acts of third parties. In the end, the work shows that the classic criteria for the solution of these conflicts are insufficient, while the adequate answer is obtained with the application of the Theory of the Dialog of the Sources, essential for effective and correct tutela in the concrete cases.
\end{abstract}

Keywords: Electronic commerce; Civil Landmarks of the Internet; Code of Consumer Protection; Dialogue of the Sources.

\section{REFERENCIAS}

AMARAL NETO, Francisco dos Santos. A equidade no Código Civil brasileiro. Cadernos do CEJ. Brasília, n. 25, abr./jun. 2004.

ALEXY, Robert. Teoria da argumentação jurídica. Trad. Zilda Hutchinson Schild Silva. São Paulo: Landy, 2001.

BAUMAN, Zygmunt. A ética é possível num mundo de consumidores? Rio de Janeiro: Zahar, 2011.

BOBBIO, Norberto. Teoria do ordenamento jurídico. Brasília: Universidade de Brasília (UnB), 1999. 
CAVALIERI FILHO, Sergio. Programa de responsabilidade civil. 12.ed. ampl. e rev. São Paulo: Atlas, 2015.

COELHO, Fábio Ulhoa. Curso de direito comercial: direito de empresa. 13. ed. São Paulo: Saraiva, 2012.v. 3.

DIAS, José de Aguiar. Da responsabilidade civil 6. ed., rev. e ampl. Rio de Janeiro: Forense, 1979. v. I.

LARENZ, Karl. Metodologia de la ciencia del derecho. Trad. Enrique Gimbernat Ordeig.

Barcelona: Ediciones Ariel, 1966.

LEONARDI, Marcel. Responsabilidade civil dos provedores de serviços de internet. São Paulo: Juarez de Oliveira, 2005.

LORENZETTI, Ricardo Luis. Comércio eletrônico. Trad. de Fabiano Menke. São Paulo: Revista dos Tribunais, 2004.

MARQUES, Cláudia Lima. Confiança no comércio eletrônico e a proteção do consumidor: (um estudo dos negócios jurídicos de consumo no comércio eletrônico). São Paulo: Revista dos Tribunais, 2004.

Contratos no código de defesa do consumidor: o novo regime das relações contratuais. 5. ed. rev. atual. e ampl. São Paulo: Revista dos Tribunais, 2005.

"Diálogo das fontes". In: BENJAMIN, Antônio Herman Vasconcellos; MARQUES, Cláudia Lima; BESSA, Leonardo Roscoe. Manual de direito do consumidor. 4. ed. rev., atual. e ampl. São Paulo: Revista dos Tribunais, 2012.

MARTINS, Guilherme Magalhães. Responsabilidade civil por acidente de consumo na internet. São Paulo: Revista dos Tribunais, 2008.

PINHEIRO, Patricia Peck. Direito digital. 5. ed. São Paulo: Saraiva, 2013.

REINALDO FILHO, Demócrito Ramos. Responsabilidade por publicações na internet. Rio de Janeiro: Forense, 2005.

ROSENVALD, Nelson. Direito civil: teoria geral. 5. ed. Rio de Janeiro: Lumen Juris, 2008.

TARTUCE, Flávio. Manual de direito civil 2. ed. rev., atual. e ampl. Rio de Janeiro: Forense; São Paulo: Método, 2012.

TEIXEIRA, Tarcisio. Comércio eletrônico: conforme o Marco Civil da Internet e a regulamentação do ecommerce no Brasil. São Paulo: Saraiva, 2015.

Saraiva, 2015.

Curso de direito e processo eletrônico: doutrina, jurisprudência e prática. 3. ed. atual. e ampl. São Paulo: Saraiva, 2014.

Curso de direito e processo eletrônico: doutrina, jurisprudência e prática. 2. ed. atual. e ampl. São Paulo:

Marco civil da internet comentado. São Paulo: Almedina, 2016.

Trabalho enviado em 08 de setembro de 2017.

Aceito em 29 de outubro de 2017. 